This item was submitted to Loughborough's Research Repository by the author.

Items in Figshare are protected by copyright, with all rights reserved, unless otherwise indicated.

\title{
Students' views on their transition from school to college mathematics: rethinking "transition" as an issue of identity
}

PLEASE CITE THE PUBLISHED VERSION

http://dx.doi.org/10.1080/14794802.2011.585824

\section{PUBLISHER}

Taylor \& Francis (Routledge) @ British Society for Research into Learning Mathematics

\section{VERSION}

AM (Accepted Manuscript)

\section{LICENCE}

CC BY-NC-ND 4.0

\section{REPOSITORY RECORD}

Hernandez-Martinez, Paul, Julian Williams, Laura Black, Pauline Davis, Maria Pampaka, and Geoff Wake. 2019. "Students' Views on Their Transition from School to College Mathematics: Rethinking "transition" as an Issue of Identity". figshare. https://hdl.handle.net/2134/8821. 
This item was submitted to Loughborough's Institutional Repository (https://dspace.lboro.ac.uk/) by the author and is made available under the following Creative Commons Licence conditions.

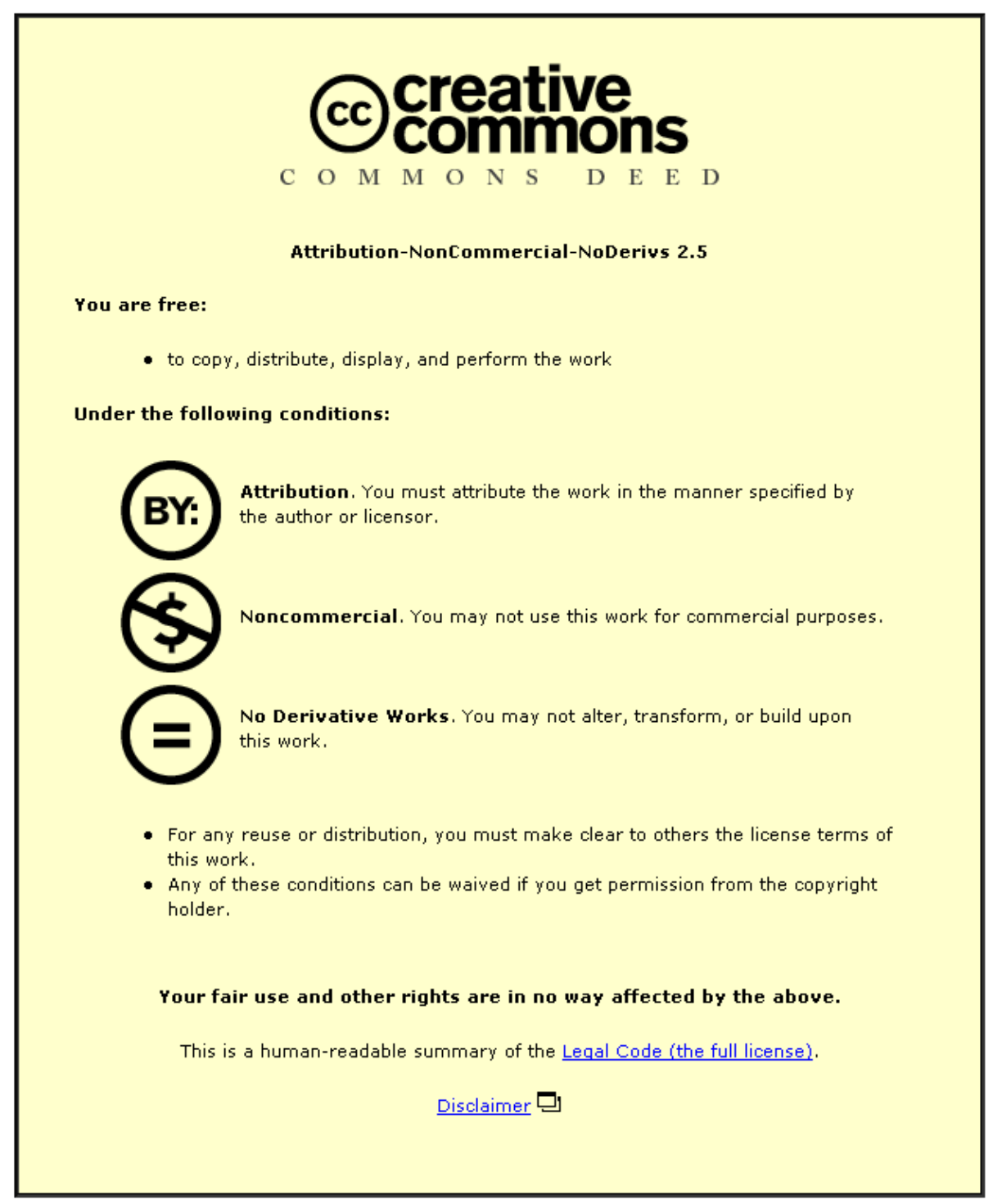

For the full text of this licence, please go to: http://creativecommons.org/licenses/by-nc-nd/2.5/ 
The final published version is available at the publisher's website: www.tandf.co.uk

\title{
Students' views on their transition from school to college mathematics: rethinking 'transition' as an issue of identity
}

\author{
Paul Hernandez-Martinez ${ }^{\mathrm{a}}$, Julian Williams ${ }^{\mathrm{b}}$, Laura Black $^{\mathrm{b}}$, Pauline Davis ${ }^{\mathrm{b}}$, \\ Maria Pampaka ${ }^{\mathrm{b}}$ and Geoff Wake \\ ${ }^{a}$ Loughborough University, UK; ${ }^{b}$ University of Manchester, UK; ${ }^{c}$ University of Nottingham, UK
}

\begin{abstract}
We examine the transition from school (compulsory education) to college (postcompulsory/pre-university) of students who are continuing their mathematical education. Previous work on transition between institutions suggests that transitional problems can be critical, and students often regard mathematics as 'difficult' during transitional periods. However, our analysis of students' interviews showed a more positive discourse, one of reported challenge, growth and achievement; transition was not seen as an obstacle but as an opportunity to develop a new identity. Particularly in relation to mathematics, this was reflected in a need for a better understanding of the subject, and for being more responsible for their learning. Thus, we propose to re-think transition as a question of identity in which persons see themselves developing due to the distinct social and academic demands that the new institution poses. Conceptualising transition in this way could have important practical implications for the way that institutions support students' transition.
\end{abstract}

Keywords: transition; post-compulsory education; identity

\section{Introduction}

In our aim for a better understanding of the transition from school (compulsory education: $\mathrm{GCSE}^{1}$ ) to college (post-compulsory/pre-university education: A-level ${ }^{2}$ ) of students who are continuing their mathematical education, we draw on data coming from our projects Widening Participation in Mathematics Programmes in Further and Higher Education, and Transition into Mathematics at Post-Compulsory Education $^{3}$. We investigate this transition from the students' perspective, and for this purpose draw on data from our two projects, mainly on biographical interviews with students before and after the transition. Our claim is that our students' stories of transition as troubled or problematic (particularly related to mathematics) were largely balanced by a more positive discourse of challenge, growth and achievement, something that is barely accounted for in the existing literature. We will therefore conclude that the literature on transition should be re-read in this more positive light: transition can be viewed as growth of identity, largely due to the challenges and demands that the new institution poses, where the chance to become a new person can be exploited by many learners.

TO CITE THIS PAPER:

Hernandez-Martinez, P., Black, L., Williams, J., Davis, P., Pampaka, M. and Wake, G. (2011) Students' views on their transition from school to college mathematics: rethinking 'transition' as an issue of identity. Research in Mathematics Education, 13:2, 119-130, Taylor \& Francis. 


\section{Institutional transition}

The educational research literature mostly refers to primary-secondary school transition (see Galton 2000 IJER special issue on school transfer and transition; Schagen and Kerr 1999), and there is now a growing literature on transition to university (see Gueudet 2008). However, the issue of transition to post-compulsory/ further education ${ }^{4}$ is relatively under-researched. The existing research on institutional transitions in general suggests that there are three broad areas of concern:

1. social dimension: this involves students becoming comfortable in the new institution, finding their way round, making new friends, and so on. These so called 'social discontinuities' relate to the students' sense of belonging to the new institution (Anderson et al. 2000);

2. continuity of curriculum and pedagogy: there is an awareness of the 'gap' between practices on either side of the transition, with implications for action to minimise the potentially risky consequences for learners by trying to 'bridge the gap' (Shagen and Kerr 1999);

3. individual progression: the receiving institution needs to become aware of, and take account of, the individual history and progression of each learner; the exporting institution needs to provide relevant, adequate and timely information that the receiving institution can trust and use (Mann 1997).

As is evident from these concerns, transition is generally viewed in this literature as a problem rather than an opportunity. There are only a few studies, to our knowledge, that have suggested that transitional periods can be chances for learners to develop new positive identities. For example, Lucey and Reay (2000) describe the sense of excited anticipation of students in transition to secondary school, and Reay (2002) depicts a discourse of 'growth' from mature students on transition into higher education. Drawing on the case study data in our projects, we can say that our case study teachers' perceptions of the problems of transition mirror this literature: the GCSE course is said to be inadequate preparation for many students with pass grades (especially grade C, but increasingly also grade B) for AS level study: students' algebra is usually mentioned by these teachers as the key problem.

Additionally, many of the teachers in our projects also reported their concerns about students not being suitably prepared to be autonomous learners, a problem that has been well documented and analysed in the literature (Väljataga and Fielder 2009, Glynn, 1985). This problem was especially mentioned in regard to coursework. In one college, 'homework' clubs were laid on at lunch times for students, and those on $\mathrm{EMA}^{5}$ grants were expected to attend regularly in order to keep their grant.

Some of our students reported very bad experiences of mathematics teaching in GCSE classes, with many different teachers, supply cover, and so on. Behaviour and discipline in GCSE classes is also often said to have been poor, and students may look forward to better behaviour, and not expect a need for discipline or control by their teachers.

\section{Difficulties in progression with mathematics}

There is a body of literature on mathematical concept development (mainly from the psychology of mathematics education community), which we briefly outline. One 
could adopt several (not necessarily commensurate) theoretical perspectives on concept development (Piagetian stages, process-object reification, procept-formation, threshold concepts). However, these all lead to the same broad conclusions as follows:

i. there are some key moments in mathematical concept development that learners find difficult, and these arise when there is a characteristic shift in perception of mathematical objects: these signal dangerous moments that challenge students' confidence, as well as their cognitive development (Gray et al. 1999);

ii. it is generally agreed that these key moments include at least the following: rational numbers/multiplicative field (at approximately 1016 years old); variable/algebra (at approximately $13 \quad 16$ years old); infinitesimals/calculus and proof (at approximately 1620 years old), (Charalambous and PittaPantazi 2007; Malisani and Spagnolo 2009; Tall 1992).

Therefore, these suggest cognitive shifts in mathematical perspective that may be associated with transitions at 11 (primary-secondary), 16 (secondary-college) and 18 (college-university), and which are likely to add to learners' perception of 'troubles'.

In addition to this literature, there is some evidence related to mathematics options, and choice to study mathematics at 16: in particular, Brown, Brown and Bibby (2008) report reasons for NOT studying mathematics post-16 (students say maths is too hard, not relevant, disliked or boring), and 'enjoyment' of mathematics is the main factor explaining higher than average participation rates (when achievement and gender are accounted for). These authors' review of literature also suggests that:

i. post-compulsory participation trends are falling in other countries (although in recent years participation in post-compulsory mathematics in the UK has been slowly growing);

ii. there is a correlation of participation with achievement and attitudes, and a continuing residual under-participation of girls.

Our own literature review for the projects led us to work with 'self-efficacy' as the most important attitudinal subjective factor likely to influence intentions to continue further study (see Pampaka et al. this issue): but we do not know of any literature in the UK regarding pre-/post-compulsory education transition relevant to this.

\section{Theoretical perspectives on subjective experience of identity in transition}

In this paper we take Cultural Historical Activity Theory (CHAT) as our main analytical framework to examine the developing identity of our students as they engage in different transitional activities.

Identity as a theoretical construct has a longstanding history, and recently it is "experiencing an obvious renaissance, with its comeback even more impressive than its original appearance" (Sfard and Prusak 1995, 15). However, we want to distance ourselves from other related concepts such as personality, character or nature, that could suggest biological characteristics or given attributes of individuals; instead, we 
see individuals as active participants in social practices and, consequently, constructing their identities through the relationships they develop within social institutions and groups.

Activity theory perspectives on identity seek to study the individual-social dialectic within the context of the communal, 'object-oriented' activity (Leontiev 1978); identity in that respect is seen as a product and by-product of activity in which, through their agency, people produce and reproduce themselves and others in the community (Engeströ $\mathrm{m}$ 1987).

Recent developments in CHAT perspectives provide for an analysis of 'identity in practice' that helps us to understand how subjective engagement in practices may constitute, or at least mediate, the person's formation of social identities. Holland et al. (1998), drawing on Vygotsky, Bakhtin, Bourdieu and others, put forward the concept of 'positioning' in 'figured worlds' to explain how identities are developed "through continued participation in the positions defined by the social organisation of those worlds' activity" (41), therefore constructing the 'self in practice' through their engagement in activity (see also Stetsenko and Arievitch 2004). It is through this concept that we realise that students construct their identities as they travel from one institution (school) to the other (college), where they encounter different social relations and most of them are positioned in different, new ways, by the new institution.

Furthermore, Beach (2003) defines transition as a developmental change in the relation between an individual and one or more social activities. He provides us with the concept of 'consequential transitions' when these "shift the individual's sense of self or social position" (42) and the "person experiences becoming someone or something new" (41). These types of transition, which change the 'sense of self', are associated with the kind of experiences narrated by the students in our projects. But, in 'consequential transitions', not only do individuals change as a result of the transition, the activities in which they engage also change. For example, mathematics learning at college can become a 'new' activity with different motives of engagement from those at school; for instance, mathematics at college is 'voluntary' (no longer part of a compulsory curriculum), and many students consider it as part of a potential route to university and a professional career. In this sense, we have argued elsewhere (Black et al. 2010) that a student's 'leading identity' defines their motive for study and shapes their relationship with mathematics. For example, a leading identity of 'becoming an engineer' could define a student's motive to engage in postcompulsory mathematics as a way to realise a longed-for aspiration.

In this paper, we propose to see transition from the perspective of the students who are engaging in activity, and therefore constructing the self in practice, because what is consequential for them might not be consequential for the teachers or the institutions. This has important implications for the kind of policies and practices adopted to support the transition. For example, we believe that it might be a mistake to attempt to nullify different challenges that college poses to individuals by an unwarranted softening of the institutional expectations. Instead, we believe students should be supported to overcome these challenges in a developmental way.

Finally, we take from Bruner (1996) that these self identities can be authored and told to others in biographical narratives, typically mediated by 'troubles', obstacles 
and canonical stories. In the light of these perspectives, we can see 'transition' from the point of view of the students, as they tell us of their experience of themselves, that is, their identities, as they transit from school into college.

\section{The students' data}

The data for this paper comes mainly from students' interviews, but our projects' case studies included interviews with several teachers and managers and observation of different mathematics lessons, amongst other relevant data.

The students on our first 'transition' project were selected from four different schools in the UK. These schools are feeder schools of two of the colleges on our second project (Widening Participation). These were students with predicted GCSE mathematics grades $\mathrm{B}$ to $\mathrm{A}^{*}$, which are normally those who would consider taking mathematics at AS level. Very few students with a predicted grade $\mathrm{C}$ consider continuing with mathematics at AS, or are encouraged to do so; and it was indeed very difficult to find such students in our 'transition' project.

The students on our second project were selected from five different colleges across the UK, and they were mainly students considered 'at risk' in terms of their GCSE mathematics grades (B or below) or their socio-economic background (coming from neighbourhoods where participation in higher education is typically low). All of these students were taking a course in mathematics (traditional AS, Use of Mathematics AS, or Vocational Engineering $\mathrm{BTEC}^{6}$ ) at the time when the project started, and many of those taking the traditional AS mathematics who only achieved a GCSE mathematics grade $\mathrm{C}$ were taking compulsory extra lessons provided by their colleges.

For the purpose of this paper, we considered the data coming from interviews with students (n 25) on our first project, either during their summer holidays before going into college or during the induction week at college. In this interview, we asked students about their educational background, their school experiences with mathematics and their expectations for college.

In relation to our second project, we considered the data coming from interviews with students (n 47) during their first weeks at college and again at the end of their AS year (although some of them had dropped out by this time or were repeating a year). During their first interview, we asked these students about their educational background, their experiences from school to college, particularly with mathematics, and their expectations for the future. During the second interview, we asked again about their previous experiences with mathematics and how these influenced their dispositions and choices for the future.

All interviews were then coded for statements on identity (self-identity and identity in practice), and these statements were then coded for particular themes in which we were interested, for example: aspirations, influences on aspirations, views about mathematics (e.g. maths as enjoyable, maths as useful), experiences with transition, and so on. For the purpose of this paper, we took into account the codes that referred to students' statements (n 106) about their experiences with transition (for example: expectations for college, transition to traditional AS, transition to AS Use of Mathematics). 


\section{Results: categories of troubles/problems in transition}

In sorting all the comments that students made relating to transition, we begin with the three categories: (i) social dimension; (ii) continuity of curriculum/pedagogy; and (iii) individual-progression/differences. In this, we exclude references to more complex transitions, e.g. immigrants coming from overseas for whom English was an issue to begin with, or who found the English culture very 'laissez-faire' with regard to discipline.

\section{(i) The social dimension}

The social aspects of transition were mentioned by 16 out of 25 students in our first project as being one of the most important (but worrying for most of them) issues in going to college.

For instance, $\mathrm{S} 2^{7}$ mentioned that he imagined the start of college would be "quite nerve-racking, with quite a lot of new people and teachers and a completely different school". However, this anxiety was then balanced with a more positive attitude towards the future: "... but I think once we get used to it it'll be quite enjoyable if there's a lot more interactive subjects and meeting new people". S20 shared a similar view, by acknowledging that the start of college would be "quite scary, also exciting, as there will be a lot of different people there".

Others, like S6, expressed their feelings towards the new social setting as an 'exciting' personal opportunity to develop in a 'better' environment:

I think I'm quite excited at being ... in a way as we're getting up to leaving school I was getting quite excited because of going somewhere new and you get to meet loads of different people that are coming from other different secondary schools that I've never met before.

In general, all of these students adopted S7's attitude of "looking forward to the new experience".

In the case of our students in the second project, this attitude was expressed in their post-hoc rationalisations as a feeling of growing,-up and 'improving' oneself by expanding one's social life. For instance, P95 recalled that she "used to be quite shy, so I think I've got a lot more confident over the year. I think that probably changed the most ... just talking to new people, like, new ideas". And P101 reported that what he enjoyed most about the transition was "mostly friendships ... because I mostly hang around with people older than me so I have to act older as well'. The difficulty of the work was balanced with this expansion of the social horizons, for instance, P65 thought that going to college was about "working harder" but also about expanding his social life: "my social life got better as well...". And P67 said that, as the year went on, "you start to know other people (not just those from your school) and you relate with other people, and it just improves you".

P61 was an unusual case as, for her, going to college was said to be largely about the college social life, having nothing better to do, and getting talked into coming to college despite not seeing the point at the time.

Choosing to study at a college close to home was commonly mentioned, although it was not always clear if this was a social issue or one of convenience, or finance; and in many cases there was virtually no choice of college to consider. 
This social sense of growing up is not confined to the purely 'social', but applies to the approach to work and study as well (see below).

\section{(ii) Coherence of curriculum and pedagogy (in mathematics)}

Practically all our students in the first project mentioned how different they expected mathematics (and other subjects) to be from their previous experience. Some of them had a better idea of what to expect (for example, talking to teachers or older siblings or attending open days), but in general the feeling was one of a 'step-up' in difficulty. This 'move up' was accompanied by a sense of personal development, in which they were leaving the 'easy' things behind and coming into a 'harder', more 'grown up' learning stage. For instance, S1, whose older sister was taking further mathematics ${ }^{8}$ at the same college that she planned to go to, said:

I know it will be completely different from GCSE because one of the teachers just told us that a completely different level of any subject comes really different and it will be very hard, so I guess I know that and I'm going to expect something really hard, yeah, so...

And S4 said "can't see how it can just jump up in difficulty that much, but it will get more complex and I guess more concentrated". However, she considers herself "ready for it, I mean I'm definitely ready to leave school".

This sense of leaving school behind and 'moving up' in terms of learning new, harder material at college is shared by most of these students. For example, S6 said:

Well I know the workload is going to probably be a lot more because we've been ... we were told when we went round for the induction day that the one thing ... they told us is that the workload would be more, because we'll be learning things, some things we'll have done before and it'll just be adding on to what we know, but some things will be totally new, so ... but I'm quite looking forward to it. I'm looking forward to something different from GCSE.

This student also mentioned the fact that she expected college to be different because "everybody at A-level has really chosen to do these A levels and everyone is going to be working, hopefully, as hard as they can, so it's a better environment to be in".

Some of these students had had previous experiences with AS level mathematics material. However, they still shared the view that the new experience was going to be difficult, but they felt confident that they would be able to achieve. For instance, S14 said:

I think it'll just be ... because in secondary school we finished our syllabus quite early and we got to start a few AS things to show what you might be doing when you first go there and it did look very difficult, but I'm going to put the work into learning everything because it's just getting different views and different methods and that.

On our second project, we found that students rationalised the experience of transition as one of facing a hard challenge that, even when they failed, helped them to grow up. 
For some of these students the transition came as a shock at first. For example, P76 said that she expected AS to be just like GCSE, but it turned out to be harder "unfortunately". In fact "it was a bit of a shock compared to GCSEs ... we were learning things I'd never seen before, it was all new".

But for most of them, this experience was seen as positive. For instance, for P60 "here is the best place I've been" (this said despite having failed the maths course the previous year because he had been, in his own words, "a bit immature"). And P67, for example, said that college was more demanding of independence: "It makes you more independent, because you don't get as much help, so you ... have to work for yourself as well. You've got to work for everything you get."

Being autonomous and independent was a recurring theme: e.g. P81 implicitly sees this as part of growing up: "it's made me more responsible and stuff..." and P89 similarly says: "It helped me to grow up a lot... GCSE was very, very, well, simple for some, where you could just blag' a few grades ...". Similarly, P104 expressed the view that:

You think it'll be the same as school and you can just slide your way through it, but now you have to put in more, it's more individual and at home you have to do all the coursework and you basically did it in class but here you have to do it yourself and achieve your grade.

Even when many students find the College work significantly harder and say they initially struggled, their stories often turn this round so that troubles become challenges to overcome. Later in the course, P6 says that although he found work "too much" at first, "completely different to GCSE (...) but now I'm coping with it", and P28 said that the transition was "big" and at first he struggled, but as he "got on with it, it's easier and we're not learning any new things, were just running over things we've already learnt".

The initial difficulty was "because it was all new and a lot more advanced ..." The 'new' things are "hard to get the hang of". P29 even relished the 'new':

It's going good, it's a lot different the work we're doing, it's all completely new, but in the maths there is a lot of linking to GCSE work so far so it hasn't been too big a step, and the method of teaching hasn't changed dramatically so it's been easy to settle in.

Another perception is that at school, they "just tell you facts, and you just have to take them as they are, they don't tell you why things are like that, so that, it's harder to understand" (P105). And P24 agreed:

I think it's a lot better than when I was doing my GCSEs and it's easier to understand... and then I know what I am doing and understand it more ... In GCSE, I don't think they explain it as much and it's more just, do questions ... I think here they go through it more and you understand easier.

Highly relevant to the perception of mathematics at the transition stage was the theme of mathematics being difficult because a lot of it was 'new' and maybe, more importantly, when it seemed disconnected from what they knew (completely different from GCSE). For instance, P137 had done very well at GCSE, but had troubles when he started college: 
My first lesson was surds... so I didn't really know what was going on, and then I just struggled with the work and it sort of scared me in the first week...'cos it's your first week so you're thinking "Oh, this is going to continue ... and it's probably going to get worse". Then a mate of mine who went to the same school, who got B overall and I got A, turned round to me and said "you're smarter than me, I don't see why you dropped it."

The 'challenge' when it is achievable is relished after the event however, as a change of identity: "I think it's harder at (college), but you can tell you are moving on". (P32) The mixture of social and work everything being new at once can sound potentially overwhelming. For P58 the change involved:

Loads of new people and getting used to your new classes, getting used to your new teachers, and trying to understand the work and that is really hard at the minute, but

I like it and I'm getting OK with it. I have student support... which is another teacher (who) makes me understand.

This was summed up by P58, who said that GCSE to A level was a big 'step' but she enjoyed overcoming the challenge.

\section{(iii) Individual information-progression in mathematics for $A S$}

The issue of individual difference and progression that has already come up several times in the above relates principally to the students with weaker GCSE backgrounds, for whom everything seems 'new' and therefore hard. From what teachers told us in interviews, this happens when the teaching assumes a 'higher' GCSE background, algebra in particular. The students usually talk of this as a 'step up'. We believe that there is no real problem with transition of information here: the colleges know the GCSE background of their incoming students well, and are conscious of their diverse strengths and weaknesses. This is, in our opinion, a curriculum pathways problem, and concomitantly a funding problem. Colleges are not funded to provide additional support to students with a GCSE mathematics grade B or C. Despite this, some colleges do have special provision for these students, in the form of extra help during the first weeks of their AS course. Students with relatively weak GCSEs said they benefited greatly from the extra help and the one to one support provided.

\section{Discussion and conclusion}

The literature on transition is reinforced in the sense that the categories are broadly supportable. However, the meaning of transition to post-compulsory education is different in the sense that 'going to college' is often about a major change in the social scene, and involves a quite radical change in mathematics curriculum (often mentioned) and classroom ambience, more than in pedagogy, although expectations for independent work come to many as a shock. The discontinuity is felt particularly by students progressing from weaker GCSE to AS, and this might be associated with the high 'drop out' rates that are recorded each year.

However, a strong theme in the students' stories, one that we had not anticipated, is that they largely tell stories of overcoming problems and troubles: this is not strongly reflected in the previous literature. We could even suggest that, the more 
severe the troubles, the more life-affirming the transition is as a record of successful growing up, in the students' narratives. Students who had gone through troubles (e.g. drop outs, resits) reflect back and see these experiences as a 'challenge' that, when overcome, allowed them to 'move on', even if 'overcoming' the problem meant that they had to change their original plans (e.g. instead of wanting to become a physicist they are now wanting to be an accountant).

Our view on transition, informed by CHAT perspectives, points us to think of it as a question of development and identity. The learner who transits from institution A to institution B in this case is moving onwards, growing up, where B makes demands for adult behaviour that A did not. This growing up is in the first place social everyone is older, the teachers talk differently, you are expected to be more autonomous, and so on. But it is also academic: the courses are more demanding in marked ways, and may in turn demand more grown up behaviour, learners do not "mess about in lessons" any more (so much).

Those who are making the transition (learners) see it as growing up, and so as 'consequential' (Beach, 2003) and therefore accept the intellectual step changes as changing, similarly, to grown-up maths. Where previously at school "you could just blag a few grades", at college students have to work harder to achieve. Learning mathematics becomes a new activity: even though there are links to GCSE concepts, college mathematics "comes really different" and the topics are "a lot more advanced", and they have to be "tackled" in a different way, a more adult way. Mathematics learning now becomes an activity where 'understanding' has to take place. There is a 'developmental change' in the relation between the individual and the activity of learning mathematics, and this change makes the transition consequential (Beach, 1999).

When learners reflect upon themselves and their experiences, they therefore want to tell of their troubles as troubles overcome in their rite of passage, as an affirmation of who they are now (i.e. as more adult). The notion here, then, is of the person in transition (or identity-in-practice) who is an object of reflection in narration: i.e. the person I was and the person I have become (or the person I am now). In this view, transition as trouble is life-affirming, an opportunity to become someone new.

It is apparently ironic that for mathematics the troubles seem largely to arise exactly from mathematics being 'all new' or at any rate too new (for some). However, this subjective experience of newness, we argue, may also be offering learners an identity change: a new learner identity, an opportunity. The fact that it is offered at a time when "everything is new" is likewise an opportunity, as well as a risk. On the other hand, students may say they managed it in the end because of support they were given by a special teacher, because they worked hard, or persisted with resits, and so on, or because there were some things that stayed the same. In each case, the 'new' is facilitated by connections. It seems, then, that the learner-perspective on transition is somewhat different from that expected the transition is an opportunity, and given the right connected support, students relish it.

Thus, we challenge the validity of transitional practices that tend to make 'college more like school' (e.g. less autonomous learning, more directed teaching), because these only take institutional perspectives on transition, leaving out the voices of those for whom transition means not only a change in curriculum, for instance, but a 'step-up', a challenge that, when supported by the institution, offers them a sense of development, the possibility of 'growing up', of becoming more active participants in society, which in the end is what education is about. 


\section{Acknowledgements}

This research has been funded by the ESRC-TLRP ${ }^{10}$ under the project Keeping Open the Door to Mathematically-Demanding Programmes in Further and Higher Education (RES-139-250241) and by the ESRC under the project Mathematics Learning, Identity and Educational Practice: the Transition into Post-compulsory Education (RES-000-22-2890). We would like to acknowledge their continued support.

\section{Notes}

1. GCSE stand for General Certificate of Secondary Education, which is an academic qualification awarded in a specified subject, generally taken in a number of subjects by students aged 1416 in secondary education in the UK.

2. A-level stands for 'Advanced level', which is a post-compulsory education qualification (normally taken at the age of 18) and the most popular route into higher education in England. A-levels can be chosen from various academic and applied subjects (normally 3 or 4 depending on interests and future plans). It usually takes two years full-time to complete an A-level, and each one is made up of AS (Advanced subsidiary first year) and A2 (second year), each of which counts as 50 percent of the overall A-level grade.

3. The first project entitled Keeping Open the Door to Mathematically-Demanding Programmes in Further and Higher Education researched different mathematics programmes and practices at AS level. More information about this project can be found in the following website: http://www.education.manchester.ac.uk/research/centres/lta/LTA Research/transmaths/tlrp/. The second project entitled Mathematics Learning, Identity and Educational Practice: the Transition into Post-Compulsory Education studied the transition from maths GCSE to AS level. More information about this project can be found at the following website: http://www.education.manchester.ac.uk/research/centres/ lta/LTAResearch/transmaths/into-college/

4. Note that in England, mathematics is not a compulsory subject at this level of education.

5. EMA stands for Educational Maintenance Grant, and is a government weekly allowance to encourage students from disadvantaged backgrounds to continue at school.

6. AS Use of Mathematics is a free-standing qualification. At the time when the project was done there was not a following-up A2 course. BTEC stands for Business and Technology Education Council, and their awards are work-related qualifications that tend to be based on practical work or coursework.

7. In this paper, we have used the following labels to identify students: S(number) for students on the 'transition' project and $\mathrm{P}$ (number) for students on the 'widening participation' project. In other papers in this issue we have preferred to use pseudonyms to identify students.

8. Further mathematics is an A-level qualification that is normally studied in addition to the mathematics A-level.

9. To blag is an expression used to denote that something important was obtained by putting in little effort; for instance, get a good grade by just revising the day before an exam.

10. The Educational and Social Economic Research Council (ESRC) is the UK's social research council that funds academic research in the social sciences, including Education. The ESRC, using university sponsorship, fund the Teaching and Learning Research Programme (TLRP) to conduct educational research in teaching and learning for over ten years in multiple phases, including one on Widening Participation in Higher Education in 2005 08. See www.tlrp.org

\section{References}

Anderson, L.W., J. Jacobs, S. Schramm, and F. Splittgerber. 2000. School transitions: Beginning of the end or a new beginning? International Journal of Educational Research 33, no. 4: $325-339$. 
Beach, K. 1999. Consequential transitions: A sociocultural expedition beyond transfer in education. Review of Research in Education 24: 101-139.

Beach, K. 2003. Consequential transitions: A developmental view of knowledge propagation through social organisations. In Between school and work: New perspectives on transfer and boundary-crossing, ed. T. Tuomi-Grohn and Y. Engeströ m, 39- 62. The Netherlands: Elsevier.

Black, L., J. Williams, P. Hernandez-Martinez, P. Davis, and G. Wake. 2010. Developing a 'leading identity': The relationship between students' mathematical identities and their career and higher education aspirations. Educational Studies in Mathematics 73, no. 1: $55-72$.

Brown, M., P. Brown, and T. Bibby. 2008. "I would rather die": Reasons given by 16-year-olds for not continuing their study of mathematics. Research in Mathematics Education 10, no. 1: 3-18.

Bruner, J. 1996. The culture of education. Cambridge, MA: Harvard University Press.

Charalambous, C.Y., and D. Pitta-Pantazi. 2007. Drawing on a theoretical model to study students' understandings of fractions. Educational Studies in Mathematics 64, no. 3: 293-316.

Engeströ m, Y. 1987. Learning by expanding: An activity-theoretical approach to developmental research. Helsinki, Finland: Orienta-Konsultit.

Galton, M., ed., 2000. Special issue on school transfer and transition. International Journal of Educational Research 33, no. 4: 321-449.

Glynn, T. 1985. Contexts for independent learning. Educational Psychology 5, no. 1: 5-15.

Gray, E., M. Pinto, D. Pitta, and D. Tall. 1999. Knowledge construction and diverging thinking in elementary and advanced mathematics. Educational Studies in Mathematics 38, nos. 1 3: 111-133.

Gueudet, G. 2008. Investigating the secondary tertiary transition. Educational Studies in Mathematics 67: 237-254.

Holland, D., W. Lachicotte, D. Skinner, and C. Cain. 1998. Identity and agency in cultural worlds. Cambridge, MA: Harvard University Press.

Leontiev, A.N. 1978. Activity consciousness and personality. Englewood Cliffs, NJ: Prentice Hall.

Lucey, H., and D. Reay. 2000. Identities in transition: Anxiety and excitement in the move to secondary school. Oxford Review of Education 26, no. 2: 191-205.

Malisani, E., and F. Spagnolo. 2009. From arithmetical thought to algebraic thought: The role of the 'variable'. Educational Studies in Mathematics 71, no. 1: 19- 41.

Mann, P. 1997. LEA strategies for effective transition from KS2 to KS3. Slough: Education Management Exchange, NFER.

Reay, D. 2002. Class, authenticity and the transition to higher education for mature students. Sociological Review 50, no. 3: 398-418.

Roth, W.-M., S. Hwang, M.I. Mafra Goulart, and Y.J. Lee. 2005. Participation, learning and identity: Dialectic perspectives. Berlin: Lehmans Media.

Schagen, S., and D. Kerr. 1999. Bridging the gap? The national curriculum and progression from primary to secondary school. Slough: NFER.

Sfard, A., and A. Prusak. 2005. Telling identities: In search of an analytic tool for investigating learning as a culturally shaped activity. Educational Researcher 34, no. 4: 14- 22.

Stetsenko, A., and I. Arievitch. 2004. The self in cultural-historical activity theory. Theory and Psychology 14, no. 4: 475-503.

Tall, D. 1992. The transition to advanced mathematical thinking: Functions, limits, infinity, and proof. In Handbook of research on mathematics teaching and learning, ed. D.A. Grouws, 495-511. Macmillan: New York.

Väljataga, T., and S. Fiedler. 2009. Supporting students to self-direct intentional learning projects with social media. Educational Technology and Society 12, no. 3: 58- 69. 